\title{
Hyponatremia Is Predictive of HSV-1 Encephalitis among Patients with Viral Encephalitis
}

\author{
Seniha Basaran, ${ }^{1}$ Serap Simsek Yavuz, ${ }^{1}$ Elif Aguloglu Bali, ${ }^{1}$ Atahan Cagatay, ${ }^{1}$ \\ Oral Oncul, ${ }^{1}$ Halit Ozsut ${ }^{1}$ and Haluk Eraksoy ${ }^{1}$
}

\author{
${ }^{1}$ Department of Infectious Diseases and Clinical Microbiology, Istanbul Faculty of Medicine, Istanbul University, \\ Istanbul, Turkey
}

\begin{abstract}
Encephalitis is an inflammatory process involving the brain parenchyma associated with neurologic dysfunction. The main causes of infectious encephalitis are viruses, including Herpes simplex virus type 1 (HSV-1). As the mortality rate of HSV-1 encephalitis could be reduced with early acyclovir treatment, it is imperative to distinguish HSV-1 encephalitis from other type of viral encephalitis as early as possible. However, sophisticated methods for definitive diagnosis of HSV-1 encephalitis are not readily available. We aimed to explore distinctive clinical and laboratory features of HSV-1 encephalitis. All of the adult patients with viral encephalitis hospitalized between 2011-2017 were enrolled, including 16 patients with HSV-1 encephalitis and 51 patients non-HSV-1 viral encephalitis. Determination of viruses in cerebrospinal fluid was performed by PCR tests. Female sex, hyponatremia, and abnormalities in MRI were independently associated with HSV-1 encephalitis $(p<0.05$ for each). In particular, hyponatremia $(<135$ $\mathrm{mEq} / \mathrm{L})$ was found in nine patients with HSV-1 encephalitis $(56.3 \%)$ and 10 patients with non-HSV-1 viral encephalitis $(19.6 \%)(p=0.005)$. As serum sodium is determined easily and quickly in clinical practice, the presence of hyponatremia among patients with viral encephalitis could be helpful for the early diagnosis of HSV-1 encephalitis before cerebrospinal fluid PCR results were available. Moreover, the presence of positive finding in MRI could further support the diagnosis. This is the first study that compared the serum sodium levels among patients between HSV-1 and non-HSV-1 viral encephalitis. We thus propose the diagnostic value of hyponatremia for HSV-1 encephalitis.
\end{abstract}

Keywords: encephalitis; herpes encephalitis; HSV-1; hyponatremia; viral encephalitis

Tohoku J. Exp. Med., 2019 March, 247 (3), 189-195. (C) 2019 Tohoku University Medical Press

\section{Introduction}

Encephalitis is an inflammatory process involving the brain parenchyma associated with clinical or laboratory evidence of neurologic dysfunction. The infectious causes of encephalitis are predominantly viruses, and a variety of viruses can lead to encephalitis. Herpes simplex virus type 1 (HSV-1) is characterized by a short replication cycle, rapid destruction of the host cell, and the ability to establish latency in human sensory ganglia. While best known as a common cause of mucocutaneous infections, HSV-1 can also cause life-threatening encephalitis (Schiffer and Corey 2015). HSV-1 causes the most severe form of viral encephalitis (70-80\% mortality) if not treated with proper antiviral agents. However, this rate of mortality can be decreased to $20 \%$ with the timely use of acyclovir (Lerner et al. 1976; Skoldenberg et al. 1984; Whitley et al. 1986). It is thus imperative to distinguish HSV-1 encephalitis from the encephalitis of other etiologies as soon as possible.
Diagnosis of HSV-1 encephalitis mainly relies on the detection of the virus in cerebrospinal fluid by polymerase chain reaction (PCR) and the presence of temporal lobe abnormalities which are predominantly unilateral and may have associated mass effect on brain imaging including magnetic resonance imaging (MRI) and computed tomography (CT). PCR detection of HSV-1 DNA in the cerebrospinal fluid (CSF) is highly sensitive (96-98\%) and specific (94-100\%) and is the gold standard for the diagnosis of HSV-1 encephalitis (Aurelius et al. 1991; Guffond et al. 1994; Lakeman and Whitley 1995; Tebas et al. 1998), but the PCR test may not be available all over the world. Moreover, the test results could be delayed until 24-48 hours and false negative results could be seen (Weil et al. 2002). We therefore need to find some quick, easy to perform and widely available laboratory tests or clinical features that suggest the disease, especially in the early stages of the disease. As the biochemical analysis of serum is widely available and easy to perform, it would have been useful to define some bio-

Received November 15, 2018; revised and accepted March 7 2019. Published online March 20, 2019; doi: 10.1620/tjem.247.189.

Correspondence: Seniha Basaran, Department of Infectious Diseases and Clinical Microbiology, Istanbul Faculty of Medicine, Istanbul

University, Turgut Ozal cad, Fatih, Istanbul 34104, Turkey.

e-mail: senihabasaran@yahoo.com 
chemical parameters that would indicate HSV-1 encephalitis. In this study, by comparing clinical and laboratory features of the patients with HSV-1 encephalitis with those with non-HSV-1 viral encephalitis, we explored distinctive clinical and laboratory features of HSV-1 encephalitis.

\section{Material and Methods}

\section{Study population and design}

The present study included patients who were hospitalized in our clinic from January 2011 to January 2017 with encephalitis and who met the criteria for definitive encephalitis (Bradshaw and Venkatesan 2016). To exclude acute disseminated encephalomyelitis (ADEM), autoimmune encephalitis and other neurological entities, all of the patients admitted to the emergency neurology department and were evaluated by a neurologist first. After that, the patients were evaluated by our department and the patients diagnosed with infectious encephalitis were hospitalized in our clinic. After excluding patients with either bacterial or tuberculous encephalitis, only patients with a presumed diagnosis of viral encephalitis were evaluated finally. Diagnosis of viral encephalitis was made by compatible clinical and laboratory findings including CSF and blood analyses. Clinical and laboratory features of the patients were retrieved from the hospital database retrospectively. Cell count, glucose and protein levels, Gram and Ehrlich-Ziehl-Neelsen staining, bacterial culture and PCR for tuberculosis and HSV DNA were determined in all of the CSF samples obtained from patients. CSF HSV-1 DNA alone was determined with a PCR test from 2011 to 2014, and HSV-1 DNA along with varicella-zoster virus (VZV) DNA, cytomegalovirus DNA, Epstein-Barr virus (EBV) DNA, herpesvirus 6 and 7 DNA, enterovirus RNA, parvovirus B19 DNA, adenovirus DNA, and parechovirus RNA were determined with a multiplex PCR test from 2015 to 2017.

Those patients who were found to be positive for HSV-1 DNA in their CSF with compatible clinical findings were categorized as having HSV-1 encephalitis and those who were found to be negative for HSV-1 DNA in their CSF were categorized as having non-HSV-1 viral encephalitis.

Cranial CT or MRI findings were regarded as compatible with HSV-1 encephalitis if abnormalities in the temporal lobe, especially medial temporal lobe structures (the amygdala, hippocampus, and uncus), the inferior-frontal lobe structures (the cingulate gyrus and orbital frontal cortex), and insular cortex, with or without associated mass effect were determined (Gnann and Whitley 2017).

The study was approved by the Clinical Research Ethics Committee of Istanbul University, Istanbul Faculty of Medicine.

\section{Data collection and outcomes}

The following variables were recorded for both patients with and without HSV-1 encephalitis: sex, age, complaints and the duration, presence of upper respiratory tract infection (URTI) symptoms before encephalitis, the season in which the patient was admitted, other comorbidities, physical findings, antiviral treatments, neurological sequelae, in-hospital mortality, total duration of hospital stay, cytological and biochemical CSF findings, CSF HSV-1 DNA, other CSF viral PCR results (if available), serum protein, glucose, creatinine, sodium, potassium, chloride and C-reactive protein (CRP) levels, whole blood count, cranial CT and/or MRI and electroencephalography findings.

\section{Statistical analysis}

Statistical analysis was done with the Statistical Package for Social Sciences (SPSS) 16.0 (SPSS Inc., Chicago, IL, USA). While $\chi^{2}$ test, Student's $t$-test, and Mann-Whitney $U$ tests were used for univariate analysis. Logistic regression analysis was used for multivariate analysis. A $p$ value of $<0.05$ was considered to be significant.

\section{Results}

Epidemiologic, clinical and laboratory features of patients with or without HSV-1 encephalitis

During the study period, a total of 67 patients with diagnosis of viral encephalitis were hospitalized in our clinic. While only HSV-1 DNA was investigated in CSF samples of 56 patients, multiplex PCR tests including HSV-1 and other viruses were performed for 11 patients. Of these 67 patients, 16 were diagnosed as having HSV-1 encephalitis, because of positivity for HSV DNA in their CSF by PCR. There was also one encephalitis patient with each of HSV-2, VZV, and EBV. Patients with or without HSV-1 encephalitis were compared according to their clinical and laboratory findings (Table 1).

Patients with HSV-1 encephalitis were older and more frequently female compared with patients with non-HSV-1 viral encephalitis ( $p$ values of 0.012 and 0.038 , respectively). There was no significant difference between the groups according to the seasonal appearance of the cases ( $p$ $=0.155)$. The most frequently reported complaints were fever and headache, while the most frequently determined physical finding were altered sensorium and dysphasia in both groups. Patients with non-HSV-1 viral encephalitis reported more frequently symptoms of upper respiratory tract infection prior to encephalitis $(p=0.028)$. We also found that the time from the beginning of the symptoms to the hospital admission was 3 days shorter among patients with HSV-1 encephalitis, but the difference was not statistically significant $(p=0.131)$.

The severity signs of encephalitis including unconsciousness and disorientation were found to be more frequent in non-HSV-1 viral encephalitis compared with HSV-1 encephalitis, and convulsions were seen more frequently among cases with HSV-1 encephalitis compared with non-HSV-1 viral encephalitis; however, none of them reached statistical significance (Table 1).

Lymphocytic pleocytosis, normal glucose levels, and mildly elevated protein levels were the frequently encountered CSF findings in both groups (Table 1). By contrast, serum sodium levels were significantly lower among patients with HSV-1 encephalitis than those with nonHSV-1 viral encephalitis $(p=0.004)$. Indeed, hyponatremia $(<135 \mathrm{mEq} / \mathrm{L})$ was found in $56.3 \%$ of 16 patients with HSV-1 encephalitis and $19.6 \%$ of 51 patients with nonHSV-1 viral encephalitis $(p=0.005)$.

Brain imaging results of patients with or without HSV-1 encephalitis

Cranial MRI findings compatible with HSV-1 enceph- 
Table 1. Comparison of epidemiological, clinical and laboratory features of patients with Herpes Simplex Virus-1 and other viral encephalitis.

\begin{tabular}{|c|c|c|c|}
\hline Characteristics & $\begin{array}{l}\text { Patients with HSV-1 } \\
\text { encephalitis } \\
(n=16)\end{array}$ & $\begin{array}{l}\text { Patients with other viral } \\
\text { encephalitis } \\
(\mathrm{n}=51)\end{array}$ & $p$ value \\
\hline Age, mean \pm SD & $53.37 \pm 16.59$ & $44.82 \pm 17.65$ & 0.088 \\
\hline Age $>50$ years, $n(\%)$ & $11(68.8)$ & $17(33.3)$ & 0.012 \\
\hline Sex, female, n (\%) & $10(62.5)$ & $17(33.3)$ & 0.038 \\
\hline Season, winter, n (\%) & $9(56.3)$ & $18(35.3)$ & 0.155 \\
\hline Presence of fever, $\mathrm{n}(\%)$ & $12(75.0)$ & $34(66.7)$ & 0.758 \\
\hline Presence of headache, $\mathrm{n}(\%)$ & $10(62.5)$ & $31(60.8)$ & 0.902 \\
\hline Presence of nausea, n (\%) & $4(25.0)$ & $17(33.3)$ & 0.758 \\
\hline $\begin{array}{l}\text { Preceding upper respiratory tract infection } \\
\text { symptoms, } \mathrm{n}(\%)\end{array}$ & $1(6.3)$ & $18(35.3)$ & 0.028 \\
\hline Dysphasia, $\mathrm{n}(\%)$ & $11(68.8)$ & $36(70.6)$ & 0.889 \\
\hline Altered mental status, n (\%) & $10(62.5)$ & $41(80.4)$ & 0.143 \\
\hline Disorientation, $\mathrm{n}(\%)$ & $9(56.3)$ & $39(76.5)$ & 0.117 \\
\hline Duration of complaints, days, mean $\pm \mathrm{SD}$ & $6.69 \pm 4.70$ & $9.76 \pm 7.60$ & 0.131 \\
\hline Convulsion, $\mathrm{n}(\%)$ & $7(43.8)$ & $14(27.5)$ & 0.220 \\
\hline Neck stiffness, n (\%) & $4(25.0)$ & $9(17.6)$ & 0.493 \\
\hline Involvement of cranial nerves, n (\%) & $2(12.5)$ & $3(5.9)$ & 0.586 \\
\hline $\begin{array}{l}\text { Findings compatible with encephalitis in } \\
\text { EEG, } \mathrm{n}(\%)\end{array}$ & $7 / 15(46.7)$ & $34 / 49(69.4)$ & 0.109 \\
\hline $\begin{array}{l}\text { Findings compatible with encephalitis in } \\
\text { cranial } \mathrm{CT}, \mathrm{n}(\%)\end{array}$ & $1 / 15(6.7)$ & $5 / 49(10.2)$ & 1.000 \\
\hline $\begin{array}{l}\text { Findings compatible with encephalitis in } \\
\text { cranial MRI, } \mathrm{n}(\%)\end{array}$ & $13 / 15(86.7)$ & $13 / 49(26.5)$ & $<0.001$ \\
\hline Temporal lobe involvement & $13 / 15(86.7)$ & $13 / 49(26.5)$ & $<0.001$ \\
\hline Insular and limbic system involvement & $8 / 15(53.3)$ & $5 / 49(10.2)$ & 0.001 \\
\hline Neurological sequelae, n (\%) & $3 / 16(18.8)$ & $4 / 51(7.8)$ & 0.345 \\
\hline $\mathrm{CSF}$ glucose level, $\mathrm{mg} / \mathrm{dL}$, mean $\pm \mathrm{SD}$ & $68.25 \pm 30.78$ & $71.04 \pm 28.42$ & 0.577 \\
\hline Serum glucose level, $\mathrm{mg} / \mathrm{dL}$, mean $\pm \mathrm{SD}$ & $160.78 \pm 100.44$ & $128.35 \pm 56.98$ & 0.213 \\
\hline CSF protein level, mg/dL, mean $\pm \mathrm{SD}$ & $389.09 \pm 255.63$ & $463.04 \pm 440.39$ & 0.571 \\
\hline CSF neutrophil count, $/ \mathrm{mm}^{3}$, mean $\pm \mathrm{SD}$ & $6.14 \pm 6.41$ & $14.12 \pm 30.93$ & 0.750 \\
\hline CSF lymphocyte count, $/ \mathrm{mm}^{3}$, mean $\pm \mathrm{SD}$ & $142.71 \pm 147.49$ & $104.20 \pm 159.69$ & 0.302 \\
\hline CSF erythrocyte count, $/ \mathrm{mm}^{3}$, mean $\pm \mathrm{SD}$ & $30.0 \pm 81.14$ & $82.79 \pm 321.78$ & 1.000 \\
\hline $\begin{array}{l}\text { Serum creatinine level (admission), } \mathrm{mg} / \mathrm{dl} \text {, } \\
\text { mean } \pm \mathrm{SD}\end{array}$ & $0.94 \pm 0.63$ & $1.20 \pm 1.12$ & 0.142 \\
\hline $\begin{array}{l}\text { Serum creatinine level (discharge), } \mathrm{mg} / \mathrm{dL} \text {, } \\
\text { mean } \pm \mathrm{SD}\end{array}$ & $0.94 \pm 0.24$ & $1.16 \pm 0.79$ & 0.656 \\
\hline Blood leucocyte count, $/ \mathrm{mm}^{3}$, mean $\pm \mathrm{SD}$ & $9,706 \pm 2,736$ & $9,131 \pm 2,996$ & 0.497 \\
\hline Serum CRP level, mg/L, mean $\pm \mathrm{SD}$ & $11.05 \pm 15.97$ & $16.11 \pm 21.43$ & 0.180 \\
\hline Serum sodium level, $\mathrm{mEq} / \mathrm{L}$, mean $\pm \mathrm{SD}$ & $132.56 \pm 6.88$ & $137.47 \pm 3.84$ & 0.004 \\
\hline Hyponatremia $(\mathrm{Na}<135 \mathrm{mEq} / \mathrm{L}), \mathrm{n}(\%)$ & $9 / 16(56.3)$ & 10/51 (19.6) & 0.005 \\
\hline Serum potassium level, $\mathrm{mEq} / \mathrm{L}$, mean $\pm \mathrm{SD}$ & $3.95 \pm 0.71$ & $4.24 \pm 0.60$ & 0.149 \\
\hline Serum chloride level, $\mathrm{mEq} / \mathrm{L}$, mean $\pm \mathrm{SD}$ & $95.25 \pm 7.65$ & $100.08 \pm 3.52$ & 0.006 \\
\hline $\begin{array}{l}\text { Total duration of hospital stays, days, } \\
\text { mean } \pm \text { SD }\end{array}$ & $24.14 \pm 7.83$ & $16.43 \pm 4.97$ & $<0.001$ \\
\hline
\end{tabular}

EEG, electroencephalography; CT, computed tomography; MRI, magnetic resonance imaging; CSF, cerebrospinal fluid; CRP, C-reactive protein.

alitis, mainly temporal lobe involvement were found more frequently among patients with HSV-1 encephalitis (13/15, $87 \%$ ) compared with HSV-1 viral encephalitis $(13 / 49,27 \%)$ $(p<0.001)$. There was temporal lobe involvement in all HSV-1 encephalitis cases, including unilateral in 10 (8 left and 2 right lobes) and bilateral in 3. Limbic and insular involvement was seen in 8/15 (53\%) and in 5/49 (10\%) patients with HSV-1 and non-HSV-1 viral encephalitis cases, respectively $(p=0.001)$. Representative images of HSV-1 encephalitis are shown in (Fig. 1).

Since hyponatremia could be the result of limbic and insular involvement, we also compared the serum sodium levels of all patients with and without limbic and insular involvement and serum sodium levels among HSV-1 encephalitis patients. Serum sodium levels of eight patients with limbic and insular involvement $(132.30 \pm 7.59 \mathrm{mEq} / \mathrm{L})$ were significantly lower than the levels of seven patients without limbic and insular involvement $(137.25 \pm 3.86$ $\mathrm{mEq} / \mathrm{L})(p=0.012)$.

A total of three patients underwent only cranial CT; namely, these patients could not undergo MRI due to seizures (one patient in HSV-1 group) or lack of cooperation 

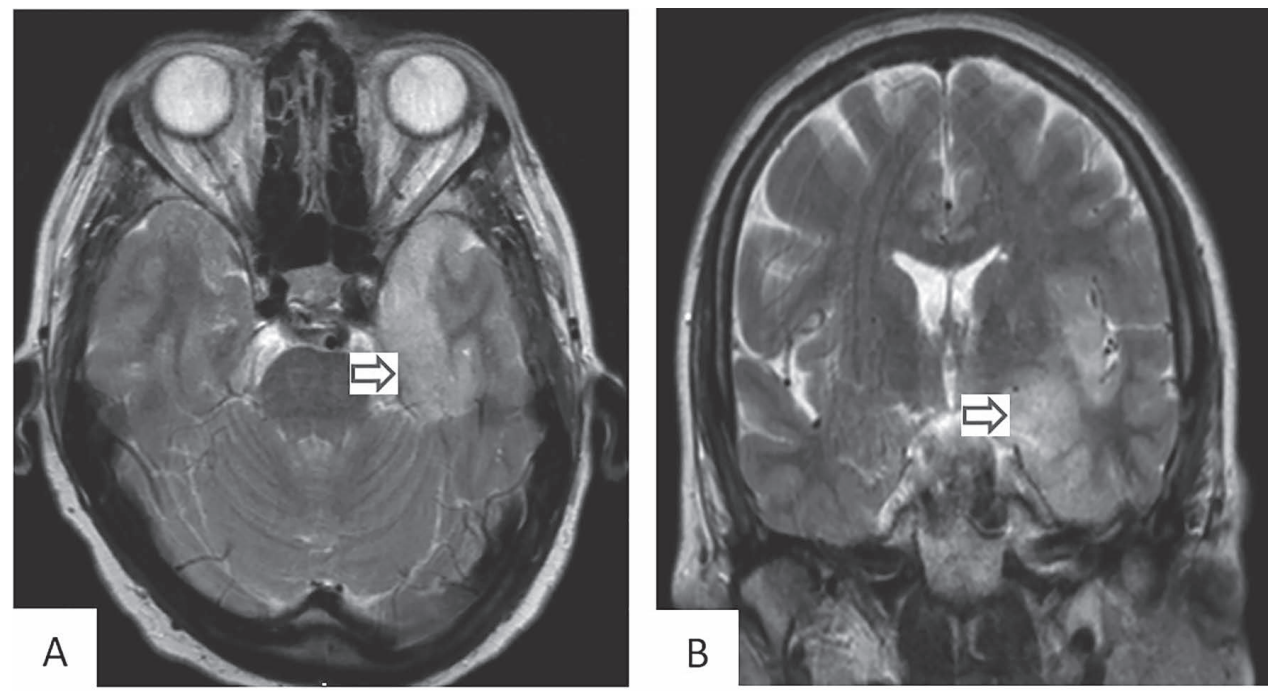

Fig. 1. MRI findings of HSV-1 encephalitis.

Axial (A) and coronal (B) T2-weighted Turbo spin echo (TSE) images in a 66-year-old woman with HSV-1 encephalitis. Note hyper-intensity in the left insular lobe that extends to the anterior temporal lobe and hippocampus.

Table 2. Results of multivariate analysis for factors associated with Herpes Simplex Virus-1 encephalitis.

Characteristics

Female sex

Findings compatible with encephalitis in cranial MRI

Hyponatremia $p$ value

0.050

0.003

0.012
OR

15.72

11.82
$95 \% \mathrm{CI}$

$1.002-39.96$

$2.59-95.26$

$1.78-79.30$

MRI, magnetic resonance imaging.

(two patients in non-HSV-1 group).

In the multivariate analysis, female sex, hyponatremia, and cranial MRI findings compatible with HSV-1 encephalitis were found to be independent factors associated with HSV-1 encephalitis (Table 2).

\section{Treatment and outcome of patients with or without HSV-1 encephalitis}

All of the patients presumed to have viral encephalitis were given $3 \times 10 \mathrm{mg} / \mathrm{kg} /$ daily (doses adjusted to renal function), IV acyclovir treatment within the first 24 hours after admission to the hospital. Acyclovir treatment was continued at least for 14 days. None of the patients were given corticosteroids or any other specific therapy other than acyclovir for encephalitis. The total duration of hospital stay was 2 and 3 weeks among patients with non-HSV-1 and HSV-1 viral encephalitis $(p<0.001)$, respectively. Only one patient with non-HSV-1 encephalitis died because of ischemic heart disease.

Neurological sequelae were seen more frequently among patients with HSV-1 encephalitis than non-HSV-1 patients (19\% vs. $8 \%)$, but the difference did not reach statistical significance $(p=0.345)$. Neurological sequelaes were seen more frequently among patients with hyponatremia ( $57 \%$ vs. $32 \%$ ), but the difference did not reach statistical significance $(p=0.065)$. Intensive care unit support was needed for 2 and 5 patients with HSV-1 encephalitis and non-HSV-1 viral encephalitis, respectively.

\section{Discussion}

HSV-1 was found to be the causative agent in $24 \%$ of viral encephalitis patients (16/67 cases) in our study, which is in accordance with the previous reports (Granerod et al. 2010; George et al. 2014; Bookstaver et al. 2017; LópezSánchez et al. 2017). We also found that the patients with HSV-1 encephalitis were older than patients with non-HSV1viral encephalitis; while $69 \%$ of patients with HSV-1 encephalitis were older than 50 years, this rate was $33 \%$ in patients with non-HSV-1 viral encephalitis. This finding is also in accordance with the previous reports (Gnann and Whitley 2017). Since HSV-1 encephalitis results mainly from the reactivation of the latent HSV-1 infection, it is not 
surprising that aging plays a facilitating role for this reactivation, as in another type of herpes virus infection, shingles. Although we found that HSV-1 encephalitis was seen more frequently in women, there are conflicting results about this issue in the literature (Riancho et al. 2013; George et al. 2014). It is known that seroprevalence of HSV-2 or incidence of CNS involvement during the primary HSV-2 infection was higher in women than in men, but this is not the case in HSV-1 infection (Corey et al. 1983; Schiffer and Corey 2015). The menstruation is a well-known precipitating risk factor for HSV-1 recurrence (Spruance 1984), which could be the reason for the increased frequency of HSV-1 encephalitis among women.

The presenting symptoms of the patients with encephalitis in our study were fever, headache, dysphasia, disorientation, altered mental status, convulsions and cranial nerve involvement similar to those reported in previous studies (Abbas et al. 2003; Mekan et al. 2005; Riera-Mestre et al. 2009; Singh et al. 2016). There was no difference in symptoms between patients with and without HSV-1 in our study, which is also in agreement with the current knowledge; the clinical presentation is nonspecific and does not reliably distinguish HSV-1 encephalitis from encephalitis caused by other pathogens (Gnann and Whitley 2017).

We also found that preceding upper respiratory tract infection (URTI) symptoms were less frequent among patients with HSV-1 encephalitis ( $6 \%$ vs. $35 \%, p=0.028$ ). This finding also could be explained by the reactivation in the pathogenesis of HSV-1 encephalitis, in which case URTI symptoms could not be expected. Some of the viral pathogens known to cause encephalitis, enter the host via the respiratory tract (e.g., adenovirus, influenza etc) and URTI symptoms could precede encephalitis in those cases. In a study including 103 encephalitis cases, URTI symptoms were seen in $61 \%, 20 \%$, and $13 \%$ of cases with acute disseminated encephalomyelitis (ADEM), non-HSV-1 viral encephalitis and HSV-1 encephalitis, respectively, and the frequency of symptoms of URTIs in ADEM cases has been explained by the fact that Mycoplasma pneumoniae and respiratory viruses are the main pathogens in the etiology of ADEM (Granerod et al. 2010). As all of our cases were admitted first to the Emergency Neurology Unit and were consulted with the Neurology Department, we could exclude noninfectious causes of encephalitis. In addition, recovering of all patients without any additional treatment except acyclovir provides a basis for a diagnosis of viral encephalitis in our study. Since the influenza virus could cause encephalitis, it will be prudent to take nasopharyngeal samples for the detection of respiratory viruses in patients with encephalitis and preceding URTI symptoms, especially during the influenza season. This investigation could help to define the causative organism in case of negative CSF viral PCR results.

All of our patients had a noncontrast cranial CT and MRI during their first 24 and 48 hours of admission, respectively. Cranial CT revealed positive findings compatible with encephalitis in $6.7 \%$ and $10 \%$ of patients with HSV-1 and non-HSV-1 viral encephalitis cases respectively, and the cranial MRI revealed positive findings in $87 \%$ and $27 \%$ of the patients with HSV-1 and non-HSV-1 viral encephalitis, respectively in our study. A positive MRI result compatible with HSV-1 was found to be an independent factor that indicates HSV-1 as the etiologic agent of encephalitis. It is well known that sensitivity of cranial CT imaging in the diagnosis of encephalitis is quite low both in HSV-1 and non-HSV viral encephalitis (56 and 19\% respectively), especially if it is taken in the early stage of the disease (Granerod et al. 2010), which is the case in our study. As a result, cranial MRI should be the first imaging method for the evaluation of patients with suspected encephalitis. If MRI is not available, negative cranial CT imaging results in the early stage of the disease should be considered cautiously, and the test should be repeated in 10 days (Granerod et al. 2016; Gnann and Whitley 2017). Positive findings compatible with HSV-1 encephalitis in cranial MRI should strongly indicate HSV-1 encephalitis.

As we found that lymphocytic pleocytosis, mildly elevated protein, and normal glucose levels were widespread in the CSF of patients with both HSV-1 and non-HSV-1 viral encephalitis, these tests could not be used to differentiate these two clinical entities. By contrast, serum sodium levels were significantly different between patients with HSV-1 and non-HSV-1 viral encephalitis, and hyponatremia (serum sodium $<135 \mathrm{mEq} / \mathrm{L}$ ) was present in $56 \%$ and $19 \%$ of patients with and without HSV-1 viral encephalitis, respectively $(p=0.005)$. Although hyponatremia was reported in every kind of infectious encephalitis (Liamis et al. 2011) and to be present in between 33\% to $83 \%$ among patients with HSV-1 encephalitis (Raschilas et al. 2002; Riancho et al. 2013; Sili et al. 2014; Misra et al. 2017), we could not find any study that compared the serum sodium levels of patients with and without HSV-1 encephalitis. Hyponatremia was found to be associated with tick-borne encephalitis in one study (Czupryna et al. 2016). Hyponatremia could be either hypovolemic hyponatremia due to fever, poor fluid intake as a result of altered mental status and vomiting, or euvolemic hyponatremia due to syndrome of inappropriate secretion of antidiuretic hormone (SIADH). Anti-edematous treatment (hyperosmolar fluids like mannitol) may also contribute to a decrease in serum sodium concentration (Czupryna et al. 2016). Limbic area, which is in the close proximity to the hypothalamo-hypophyseal system, could be involved frequently in patients with HSV encephalitis and could lead to SIADH (Rovit and Sigler 1964; Kuriki et al. 2008). As our study was retrospective in design, we were unable to evaluate the exact mechanism of hyponatremia among patients with HSV-1 encephalitis. Because limbic and insular involvement were seen more frequently in patients with HSV-1 encephalitis ( $50 \%$ vs. $11 \%$ ), and mean serum sodium level of patients with limbic and insular involvement was significantly lower than that in patients without limbic and insular involvement 
$(p=0.024)$. In a study from Spain, hyponatremia was found to be associated with poor outcome (death or sequelae) among patients with HSV-1 encephalitis (Riancho et al. 2013). All of our patients except two had mild hyponatremia and were treated easily with only fluid replacement, but two patients who had severe hyponatremia (serum sodium $<125 \mathrm{mEq} / \mathrm{L}$ ) needed intensive care. Although hyponatremia is seen in various disease conditions with the nutritional-metabolic dysregulation, we found that it is more frequent in HSV-1 encephalitis than non-HSV-1 viral encephalitis, probably because of involvement of wider brain regions. In accordance with these, insular and limbic system involvement was seen more frequently among HSV-1 patients with hyponatremia, although the difference did not reach statistical significance. Taken together, we could not use hyponatremia as a definite diagnostic tool, but as an aid to earlier diagnosis of HSV-1 encephalitis especially in the case of unavailability of HSV PCR test, or if the results of HSV-1 PCR test are delayed.

Although the mortality rate of HSV-1 encephalitis is reported to be $10-25 \%$ despite antiviral treatment (Gnann and Whitley 2017), there was no case of death among patients with HSV-1 encephalitis in our study. This could be due to early (always within 24 hours of admission) administration of acyclovir and supportive care, both of them known to reduce mortality (Hughes and Jackson 2012; Stahl et al. 2012).

As there were patients with temporal lobe involvement in the non-HSV-1 group and all of the patients were given acyclovir, one of the weaknesses of our study was the probability of inclusion of HSV-1 encephalitis cases in the nonHSV-1 encephalitis group. However, we used CSF HSV-1 DNA; the most validated, sensitive and specific diagnostic test for the diagnosis of patients with HSV-1 encephalitis, the probability of having false negative cases is rather low. Another weakness of our study is retrospective design and because of that, it was impossible for us to evaluate the exact mechanism of hyponatremia. Finally, it was impossible to evaluate all of the patient's CSF for the presence of viruses other than HSV. However, all of our patients were evaluated by Neurology Department first to exclude all the neurological entities, have clinical, radiological and CSF findings compatible with viral encephalitis, and were recovered without corticosteroids or any other specific therapy except acyclovir. Accordingly, the diagnosis as viral encephalitis should be appropriate.

In conclusion, our findings suggest that hyponatremia and compatible MRI findings are the most important predictors of HSV-1 encephalitis among patients with presumed viral encephalitis. As the serum sodium could be determined quickly and easily in routine clinical practice, the presence of hyponatremia among patients with encephalitis could be used as an early supportive adjunct for the diagnosis of HSV-1 encephalitis before CSF HSV-1 DNA results are available especially in resourcelimited countries. Moreover, the presence of positive finding compatible with HSV-1 in MRI could be supportive for the diagnosis. Future prospective studies are needed to evaluate and compare the incidence, exact mechanism and the impact of hyponatremia in patients with viral encephalitis including HSV-1.

\section{Conflict of Interest}

The authors declare no conflict of interest.

\section{References}

Abbas, B.B., Abdolvahab, A., Gholamali, Y.P., Roshanak, B. \& Mahmood, R. (2003) Clinical signs as a guide for performing HSV-PCR in correct diagnosis of herpes simplex virus encephalitis. Neurol. India, 51, 341-344.

Aurelius, E., Johansson, B., Skoldenberg, B., Staland, A. \& Forsgren, M. (1991) Rapid diagnosis of herpes simplex encephalitis by nested polymerase chain reaction assay of cerebrospinal fluid. Lancet, 337, 189-192.

Bookstaver, P.B., Mohorn, P.L., Shah, A., Tesh, L.D., Quidley, A.M., Kothari, R., Bland, C.M. \& Weissman, S. (2017) Management of viral central nervous system infections: a primer for clinicians. J. Cent. Nerv. Syst. Dis., 9, 1179573517703342.

Bradshaw, M.J. \& Venkatesan, A. (2016) Herpes simplex virus-1 encephalitis in adults: pathophysiology, diagnosis, and management. Neurotherapeutics, 13, 493-508.

Corey, L., Adams, H.G., Brown, Z.A. \& Holmes, K.K. (1983) Genital herpes simplex virus infections: clinical manifestations, course, and complications. Ann. Intern. Med., 98, 958-972.

Czupryna, P., Moniuszko, A., Garkowski, A., Pancewicz, S. \& Zajkowska, J. (2016) Comparison of hyponatremia and SIADH frequency in patients with tick borne encephalitis and meningitis of other origin. Scand. J. Clin. Lab. Invest., 76, 159-164.

George, B.P., Schneider, E.B. \& Venkatesan, A. (2014) Encephalitis hospitalization rates and inpatient mortality in the United States, 2000-2010. PLoS One, 9, e104169.

Gnann, J.W. Jr. \& Whitley, R.J. (2017) Herpes simplex encephalitis: an update. Curr. Infect. Dis. Rep., 19, 13.

Granerod, J., Ambrose, H.E., Davies, N.W., Clewley, J.P., Walsh, A.L., Morgan, D., Cunningham, R., Zuckerman, M., Mutton, K.J., Solomon, T., Ward, K.N., Lunn, M.P., Irani, S.R., Vincent, A., Brown, D.W., et al. (2010) Causes of encephalitis and differences in their clinical presentations in England: a multicentre, population-based prospective study. Lancet Infect. Dis., 10, 835-844.

Granerod, J., Davies, N.W., Mukonoweshuro, W., Mehta, A., Das, K., Lim, M., Solomon, T., Biswas, S., Rosella, L., Brown, D.W. \& Crowcroft, N.S.; UK Public Health England Aetiology of Encephalitis Study Group (2016) Neuroimaging in encephalitis: analysis of imaging findings and interobserver agreement. Clin. Radiol., 71, 1050-1058.

Guffond, T., Dewilde, A., Lobert, P.E., Caparros-Lefebvre, D., Hober, D. \& Wattre, P. (1994) Significance and clinical relevance of the detection of herpes simplex virus DNA by the polymerase chain reaction in cerebrospinal fluid from patients with presumed encephalitis. Clin. Infect. Dis., 18, 744-749.

Hughes, P.S. \& Jackson, A.C. (2012) Delays in initiation of acyclovir therapy in herpes simplex encephalitis. Can. J. Neurol. Sci., 39, 644-648.

Kuriki, A., Ishihara, K., Satoh, H., Sugie, M., Kato, H. \& Kawamura, M. (2008) Syndrome of inappropriate secretion of anti-diuretic hormone associated with limbic encephalitis due to herpes simplex virus infection: a case report. Rinsho Shinkeigaku, 48, 184-190. 
Lakeman, F.D. \& Whitley, R.J. (1995) Diagnosis of herpes simplex encephalitis: application of polymerase chain reaction to cerebrospinal fluid from brain-biopsied patients and correlation with disease. National Institute of Allergy and Infectious Diseases Collaborative Antiviral Study Group. J. Infect. Dis., 171, 857-863.

Lerner, A.M., Wilson, F.M., Lauter, C.B., Cushing, R.D., Reyes, M.P., Nolan, D.C. \& Legaspi, R.C. (1976) An estimate of the course of herpes simplex virus encephalitis. Scand. J. Infect. Dis., 8, 37-44.

Liamis, G., Milionis, H.J. \& Elisaf, M. (2011) Hyponatremia in patients with infectious diseases. J. Infect., 63, 327-335.

López-Sánchez, C., Sulleiro, E., Bocanegra, C., Romero, S., Codina, G., Sanz, I., Esperalba, J., Serra, J., Pigrau, C., Burgos, J., Almirante, B. \& Falcó, V. (2017) Infectious encephalitis: utility of a rational approach to aetiological diagnosis in daily clinical practice. Eur. J. Clin. Microbiol. Infect. Dis., 36, 641-648.

Mekan, S.F., Wasay, M., Khelaeni, B., Saeed, Z., Hassan, A. \& Sheerani, M. (2005) Herpes simplex encephalitis: analysis of 68 cases from a tertiary care hospital in Karachi, Pakistan. $J$. Pak. Med. Assoc., 55, 146-148.

Misra, U.K., Kalita, J., Singh, R.K. \& Bhoi, S.K. (2017) A study of hyponatremia in acute encephalitis syndrome: a prospective study from a tertiary care center in India. J. Intensive Care Med., 885066617701422.

Raschilas, F., Wolff, M., Delatour, F., Chaffaut, C., De Broucker, T., Chevret, S., Lebon, P., Canton, P. \& Rozenberg, F. (2002) Outcome of and prognostic factors for herpes simplex encephalitis in adult patients: results of a multicenter study. Clin. Infect. Dis., 35, 254-260.

Riancho, J., Delgado-Alvarado, M., Sedano, M.J., Polo, J.M. \& Berciano, J. (2013) Herpes simplex encephalitis: clinical presentation, neurological sequelae and new prognostic factors. Ten years of experience. Neurol. Sci., 34, 1879-1881.

Riera-Mestre, A., Gubieras, L., Martinez-Yelamos, S., Cabellos, C. \& Fernandez-Viladrich, P. (2009) Adult herpes simplex encephalitis: fifteen years' experience. Enferm. Infecc. Microbiol. Clin., 27, 143-147.
Rovit, R.L. \& Sigler, M.H. (1964) Hyponatremia with herpes simplex encephalitis. Possible relationship of limbic lesions and ADH secretion. Arch. Neurol., 10, 595-603.

Schiffer, J.T. \& Corey, L. (2015) Herpes simplex virus. In Mandell, Douglas, and Bennett's Principles and Practice of Infectious Diseases, 8th ed., edited by Bennett, J.E., Dolin, R. \& Blaser, M.J. Elsevier Saunders, Philadelphia, PA, pp. 17131730.

Sili, U., Kaya, A. \& Mert, A.; HSV Encephalitis Study Group (2014) Herpes simplex virus encephalitis: clinical manifestations, diagnosis and outcome in 106 adult patients. J. Clin. Virol., 60, 112-118.

Singh, T.D., Fugate, J.E., Hocker, S., Wijdicks, E.F.M., Aksamit, A.J. Jr. \& Rabinstein, A.A. (2016) Predictors of outcome in HSV encephalitis. J. Neurol., 263, 277-289.

Skoldenberg, B., Forsgren, M., Alestig, K., Bergstrom, T., Burman, L., Dahlqvist, E., Forkman, A., Fryden, A., Lovgren, K., Norlin, K., et al. (1984) Acyclovir versus vidarabine in herpes simplex encephalitis: randomised multicentre study in consecutive Swedish patients. Lancet, 2, 707-711.

Spruance, S.L. (1984) Pathogenesis of herpes simplex labialis: excretion of virus in the oral cavity. J. Clin. Microbiol., 19, 675-679.

Stahl, J.P. \& Mailles, A., De Broucker, T.; Steering Committee and Investigators Group (2012) Herpes simplex encephalitis and management of acyclovir in encephalitis patients in France. Epidemiol. Infect., 140, 372-381.

Tebas, P., Nease, R.F. \& Storch, G.A. (1998) Use of the polymerase chain reaction in the diagnosis of herpes simplex encephalitis: a decision analysis model. Am. J. Med., 105, 287-295.

Weil, A.A., Glaser, C.A., Amad, Z. \& Forghani, B. (2002) Patients with suspected herpes simplex encephalitis: rethinking an initial negative polymerase chain reaction result. Clin. Infect. Dis., 34, 1154-1157.

Whitley, R.J., Alford, C.A., Hirsch, M.S., Schooley, R.T., Luby, J.P., Aoki, F.Y., Hanley, D., Nahmias, A.J. \& Soong, S.J. (1986) Vidarabine versus acyclovir therapy in herpes simplex encephalitis. N. Engl. J. Med., 314, 144-149. 